\title{
IMPLEMENTASI PANGAN BERKELANJUTAN DI BALEKAMBANG MELALUI FASILITAS AQUAPONIC BERBASIS KOMUNITAS
}

\author{
Risyad Nadhifian Reksoprodjo' ${ }^{1)}$, Djidjin Wipranata ${ }^{2)}$
}

\author{
1)Program Studi S1 Arsitektur, Fakultas Teknik, Universitas Tarumanagara, op.rnadhif@gmail.com \\ 2) Program Studi S1 Arsitektur, Fakultas Teknik, Universitas Tarumanagara, djidjinellya@yahoo.com
}

\begin{abstract}
Abstrak
Pangan merupakan kebutuhan utama bagi manusia. Dengan energi dari pangan, manusia dapat melakukan aktivitas keseharian yang dapat berpengaruh terhadap kehidupan manusia. Dengan ini pangan sangat penting terhadap semua aspek kehidupan manusia, serta kondisi ekosistem bumi itu sendiri. Sayangnya, di era globalisasi ini, Sistem pangan sebagian besar dikapitalisasi. Banyak efek buruk yang diakibatkan kapitalisasi pangan ini. seperti contohnya overfarming, pemborosan SDA, dan penumpukan limbah. Hal ini berefek buruk terhadap ekosistem. Untuk itu aplikasi pangan berkelanjutan menjadi teramat penting. Pangan berkelanjutan berfokus pada bagaimana memproduksi pangan dengan cara yang positif terhadap ekologi bumi serta pengonsumsi pangan itu sendiri. Pangan berkelanjutan patut diterapkan di masyarakat perkotaan, karena volume konsumsi yang besar dan cukup berpengaruh terhadap rotasi pangan. Harapannya dengan aplikasi pangan berkelanjutan di masyarakat perkotaan, keperluan pangan sehat dan merata di masyarakat dapat dipenuhi, seiringan dengan dapat terjaganya kondisi ekosistem bumi. Fasilitas Aquaponic berbasis komunitas di Balekambang merupakan sebuah proyek eksperimental yang mengaplikasikan sistem pangan berkelanjutan di tengah komunitas pemukiman padat DKI Jakarta, spesifiknya Kelurahan Balekambang. Dengan mengkombinasikan sistem pangan Aquaponic dengan aktivitas sosial warga sekitar, proyek ini bertujuan agar sistem pangan berkelanjutan dapat diadopsi oleh warga balekambang dan menjadi sesuatu yang berasa dimiliki oleh warga sekitar, serta menghasilkan pangan sehat dan berkelanjutan bagi warga sekitar.
\end{abstract}

Kata kunci: berkelanjutan; komunitas; pangan; sosial; urban.

\begin{abstract}
Food is a primary need for humans. With energy produced by foods, humans can do daily activities that contribute to human society. Because of this, food plays a very pivotal role in human society, and the world itself. Unfortunately, in this era of globalization, food systems are commonly capitalized, which creates negative effects on earth's ecosystem. Negative effects include overfarming, overuse of natural resources, and over-wasting. This has bad effects on earth and its ecologies, that's why the application of sustainable foods in human society must be done. Sustainable food systems focus on producing food with a positive impact on the earth's ecosystem and its consumers. Sustainable foods are well suited to be implemented in urban society, due to their large consumption value which largely impacts the rotation of food systems. The hope is that with the application of sustainable foods in urban communities, the need for healthy and positive-impacting food in urban communities could be fulfilled, while also keeping earth's ecosystems intact. Balekambang community based aquaponics facility is a pilot project to provide sustainable and locally produced foods for urban residents in Jakarta, specifically in Balekambang sub-district. Using aquaponics system at its core, we combine planting and social activities to create a sustainable food ecosystem that belongs to the residents. The building itself is designed to provide optimal sunlight, airflow, and water distribution towards aquaculture and hydroponic plant systems, thus creating the year-round optimal environment for growing fish and plants.
\end{abstract}

Keywords: community; food; social; sustainability; urban 


\section{PENDAHULUAN}

\section{Latar Belakang}

Pangan merupakan kebutuhan utama bagi manusia. Tanpa pangan, makhluk hidup akan sulit dalam mengerjakan aktivitas sehari-harinya. Makanan dapat membantu manusia dalam mendapatkan energi, membantu pertumbuhan badan dan otak. Maka karena vitalnya pangan, Pangan sangatlah berpengaruh terhadap kehidupan manusia serta kelangsungan hidup di bumi. Sayangnya, di era globalisasi, sistem pangan sebagian besar dikapitalisasi. Banyak efek buruk yang diakibatkan kapitalisasi pangan, tetapi yang paling besar adalah Industrialisasi Pangan yang mengakibatkan praktik Overfarming. Dengan praktik overfarming ini, produksi pangan tidak dilakukan secara berkelanjutan, marak dengan over produksi, pemborosan sumber daya, serta penghancuran ekosistem existing di bumi. Karena efeknya yang sangat buruk terhadap lingkungan, maka perlu digalakannya konsumsi pangan berkelanjutan bagi seluruh lapisan masyarakat.

Konsumsi pangan berkelanjutan sangat penting, terutama di perkotaan karena mempunyai volume konsumsi yang tinggi. Jika masyarakat perkotaan mengkonsumsi serta memproduksi pangan berkelanjutan, maka kerusakan lingkungan di luar perkotaan karena industrialisasi pangan dapat dihindari, sehingga menjaga ekosistem di bumi secara holistic. Selain itu, memproduksi pangan sendiri juga menciptakah ketahanan pangan yang kuat, terutama di masamasa krisis, dan secara langsung membuat kualitas hidup masyarakat lebih baik. Di Jakarta, pangan berkelanjutan masih belum teriemplementasi bagus dalam kehidupan mayoritas masyarakatnya. Maka, diperlukan solusi agar masyarakat urban pemukiman padat Jakarta dapat memproduksi pangan berkelanjutan secara mudah.

Masalahnya, di pemukiman padat perkotaan yang identik terhadap masyarakat sasaran, lahan kosong tidaklah banyak serta luas, juga harga tanah cukup mahal sehingga alokasi tanah untuk menanam terbatas. Maka diperlukan solusi bagaimana memproduksi bahan pangan di lahan terbatas dengan metoda berkelanjutan yang ramah lingkungan. Salah satu solusi yang dapat diterapkan adalah bertanam aquaponic dalam skala komunitas, dimana terwujudnya fasilitas bertanam sistem aquaponic yang dikelola komunitas rukun tetangga (RT) ataupun rukun warga (RW), khususnya di pemukiman padat.

\section{Rumusan Permasalahan}

Berdasarkan latar belakang diatas, maka rumusan masalah proyek ini adalah:

- Bagaimana cara menerapkan produksi pangan berkelanjutan di masyarakat perkotaan

- Metode tanam pangan apakah yang cocok diterapkan di tengah pemukiman padat?

- Desain wadah atau fasilitas yang seperti apakah yang dapat secara optimal mendukung pertanian komunitas urban?

\section{Tujuan}

Berdasarkan rumusan permasalahan diatas, maka tujuan dari proyek ini adalah:

- Menciptakan wadah untuk memproduksi dan menanam pangan bagi warga pemukiman padat

- Menciptakan arsitektur yang dapat mengakomodir aktivitas penanaman pangan di perkotaan

- Menjadikan produksi pangan berkelanjutan sebagai bagian hidup masyarakat perkotaan padat.

\section{KAJIAN LITERATUR}

\section{Beyond Ecology}

Beyond ecology, atau melampau ekologi, adalah kondisi ekosistem dimana formasi sosialnya 
mengalami evolusi dengan percepatan. Dalam kondisi ini, kecepatan menjadi sesuatu yang paling sentral dan menjadi parameter kemajuan atau evolusi. Kecepatan ini memengaruhi aspek seperti kehidupan sosial, ekonomi, dan politik. Kemajuan atau evolusi tidak dicirikan dengan pembaharuan, tetapi dengan kecepatan. Untuk dapat melampaui ekologi, maka kita pertama harus mempelajari apa ekologi itu sendiri.

\section{Hubungan antara manusia dengan ekosistem}

Dalam ekologi, Hubungan antara manusia dengan ekosistem bumilah yang disorot dalam ekologi. Ekologi pun sangat luas, dan bisa mencapai berbagai macam organisme. Hubungan ini ada di keseharian kehidupan manusia, dan menjadi bagian utama kehidupan masyarakat (Coman \& Cioruta, 2019). Salah satu contoh hubungan yang memperlihatkan ekologi antara manusia dan lingkungan sekitarnya dapat dilihat dari bagan ini.

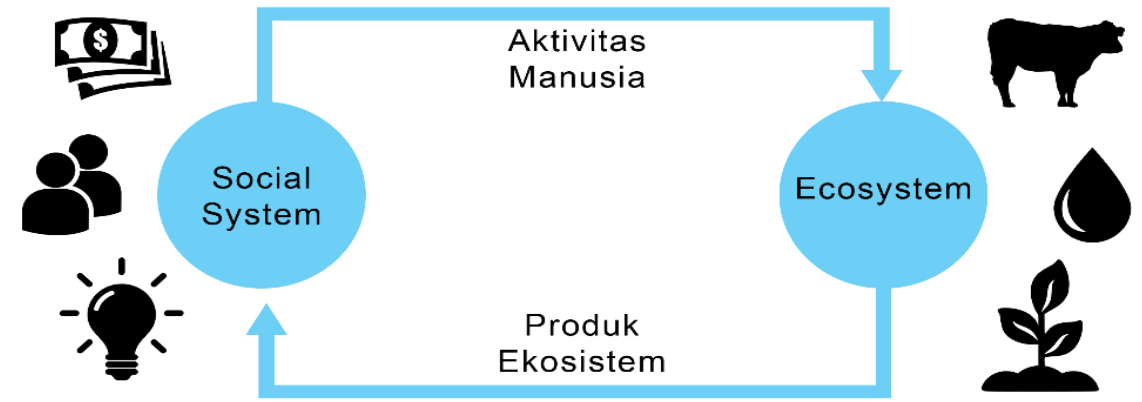

Gambar 1. Ilustrasi Hubungan Manusia \& Ekosistem Sumber : Dokumen Pribadi

Di bagan ini, populasi manusia dilambangkan sebagai social system, dengan faktor-faktor lain dalam hidup manusia seperti ilmu pengetahuan, teknologi, dan organisasi sosial. Sementara alam sekitar dilambangan sebagai ekosistem, dengan bagian-bagian ekosistem seperti binatang, mikroorganisme, dan struktur buatan manusia. Kedua saling memberikan sesuatu terhadap satu sama lain (Capra, 1996). Alam memberikan sumber daya terhadap manusia, dan aksi manusia untuk mengambil sumber daya tersebut berefek langsung terhadap kondisi alam itu sendiri. Siklus putaran ini terus berjalan jika dilakukan dengan sempurna, maka terciptalah sebuah ekologi sempurna atau yang sering dibilang ecosophy.

Ecosophy (Deep Ecology)

Ecosophy atau yang disebut dengan deep ecology, merupakan sebuah keharmonisan antara ekologi dengan manusia, atau tercapainya sebuah titik keseimbangan diantara kedua entitas tersebut. Konsep ecosophy ini menjamin kebutuhan manusia tetap dapat terpenuhi, tetapi juga menjaga kondisi serta kebutuhan ekologi di bumi itu sendiri (Devall, 1985). Kiblat pembangunan serta pengembangan masyarakat haruslah menganut konsep ini, agar ekologi bumi tidak dikorbankan semata-mata untuk kebutuhan manusia, tetapi melihat kebutuhan secara holistik agar keseimbangan alam tetap terjaga.

\section{Pangan}

Salah satu hasil alam yang sangat berkontribusi dan vital terhadap sosial masyarakat adalah pangan. Pangan atau makanan adalah suatu substansi yang dapat memberikan nutrisi terhadap manusia. Nutrisi adalah zat yang memberikan energi untuk aktivitas, pertumbuhan dan menjalankan fungsi badan (Burgess \& Glasauer, 2004). Karena sangat vital bagi manusia, maka pangan merupakan salah satu kebutuhan dasar utama manusia yang juga merupakan hak asasi manusia paling utama. 


\section{Pangan Dalam Era Globalisasi}

Dalam era globalisasi modern, banyak sekali sumber daya alam yang dikapitalisasi. Tidak terkecualikan dengan pangan atau makanan. Kapitalisme membuat pangan, sebuah kebutuhan pokok, menjadi sebuah komoditas yang diperjual-belikan dengan orientasi terhadap untung atau profit (Holt-Gimenez, 2019). Hal ini dapat dilihat dengan adanya industrialisasi agrikultur, sebuah praktek yang mengeksploitasi sumber daya pangan itu sendiri. Praktik ini telah terdata menghancurkan $75 \%$ biodiversitas bumi, memakai $80 \%$ air bersih di bumi, dan juga menciptakan $20 \%$ gas rumah kaca yang terproduksi di bumi. Hal ini sangat berefek buruk terhadap sumber daya alam dan kondisi alam bumi itu sendiri. Bukan hanya efek buruk terhadap bumi, tetapi kapitalisasi pangan juga mengancam ketahanan pangan. Karena keterikatannya dengan uang, maka ketahanan pangan bagi kaum menengah kebawah, tidak mampu, dan marginal sangat terancam, terutama di masa-masa krisis. Sangat bertolak belakang dengan kaum mampu yang masih dapat dengan mudah membeli pangan di berbagai kondisi (Holt-Gimenez, 2019). Hal ini menciptakan disparitas antara kaum mampu dengan tidak mampu, dalam sebuah kebutuhan dasar yang seharusnya dapat dimiliki oleh sesama manusia. Salah satu solusi dari masalah pangan di masa modern adalah implementasi pangan yang berkelanjutan di kehidupan seharihari.

\section{Food Sustainability (Keberlanjutan Pangan)}

Keberlanjutan pangan adalah kondisi dimana pangan yang kita konsumsi berefek positif terhadap konsumen, produsen serta alam sebagai sumber pangan itu sendiri (Gutierrez \& Hidalgo, 2020). Kondisi ini dapat dipengaruhi dengan bagaimana pangan tersebut itu di produksi, distribusi, dikemas, serta dikonsumsi. Sebuah sistem pangan yang sejatinya berkelanjutan harus memelihara manusia, binatang, lahan, komunitas serta alam. Semua manusia tanpa memandang bulu harus mendapatkan akses terhadap pangan secara merata, dan juga gaji yang wajar bagi pekerja produksi pangan. Binatang atau livestock yang akan dikonsumsi harus diproses secara alami dan manusiawi, serta menghindari overfarming. Lahan harus dapat mempertahankan biodiversitasnya dalam proses pembuatan pangan. Komunitas harus mendapat efek positif seperti peluang kerja serta peluang usaha dalam produksi serta jual beli pangan, dan yang terakhir, alam dapat dilindungi dengan memproduksi pangan secara lokal, yang mengurangi penggunaan zat kimia berpolusi serta polusi dari kendaraan distribusi (Neven, 2014). Jika semua faktor ini tercapai, maka industri pangan akan tetap dapat menghasilkan untung agar dapat berkembang, dan di saat yang sama dengan menjaga alam dan bumi, memastikan bahwa pangan masih dapat diproduksi berulang kali dan tidak habis atau rusak

\section{Urban Farming}

Urban Farming adalah praktek penumbuhan, produksi, dan distribusi agrikultur yang terjadi di dalam atau sekitar perkotaan. Urban farming memberikan berbagai solusi dalam banyak area, seperti ketahanan pangan bagi masyarakat kurang mampu, kesempatan kerja dan training untuk kaum terpuruk dan marginal, akses terjamin kepada pangan bernutrisi, dan reduced environmental impact dengan berkurangnya kebutuhan logistik dan (Food \& Agriculture Organization, 2011). Kebutuhan sumber daya untuk urban farming tidak jauh berbeda dengan agrikultur tradisional, tetapi karena lokasi aktivitasnya berada di dalam area urban yang padat, maka cara memenuhinya pun berbeda. Kebutuhan utama dalam urban farming adalah lahan, air untuk irigasi, matahari, dan tenaga manusia (Cockrall-King, 2012). Dari keempat kebutuhan ini, lahan lah yang paling susah untuk dipenuhi, karena area urban jarang mempunyai lahan luas, belum lagi dengan harga tanah yang cukup mahal di area perkotaan. Untuk penggunaan lahan optimal, maka diperlukan teknik penanaman yang tidak memerlukan lahan luas serta menghasilkan pangan banyak per meter luasan lahan. Salah satu teknik penanaman yang adalah sistem aquaponic. 


\section{Aquaponic}

Aquaponic adalah sebuah teknik yang menggabungkan aquaculture, atau mengembang biakkan ikan atau produk air lainnya dengan hidroponik, yaitu menanam tanaman tanpa medium tanah. Sistem aquaponic dapat dirancang dengan bertumpuk atau tingkat, sehingga memaksimalkan penggunaan lahan dan tingginya penghasilan pangan per meter dibandingkan produksi pangan konvensional (Riawan, 2016) .

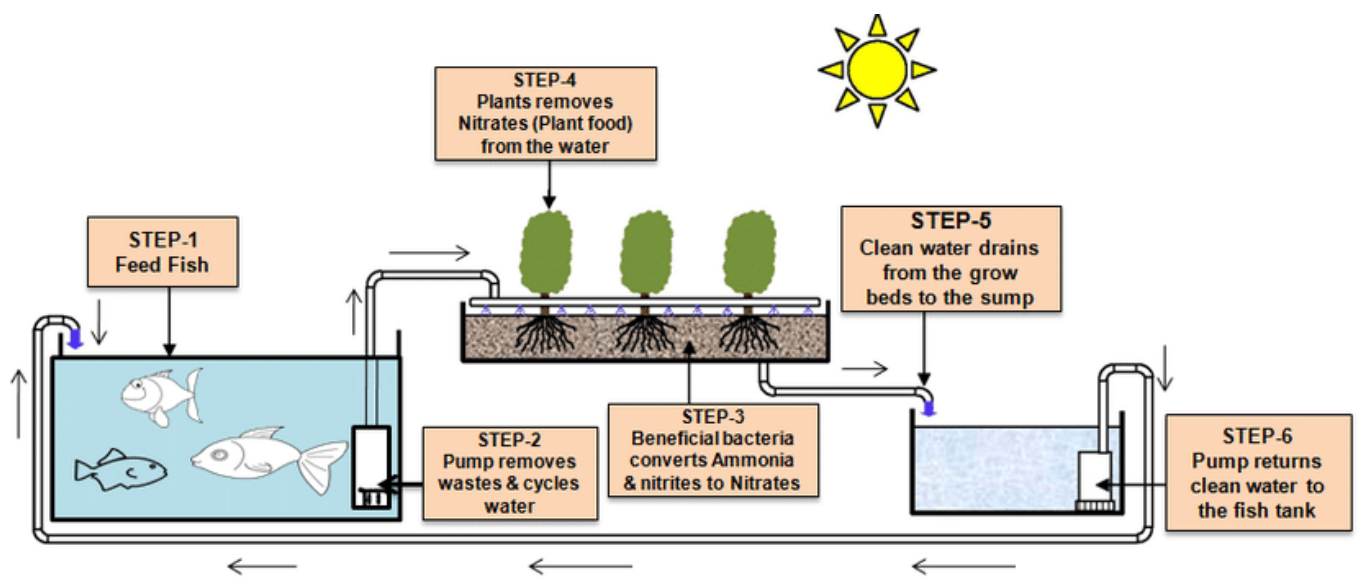

Gambar 2. Bagan Proses Aquaponic

Sumber: Researchgate.net

Penggabungan kedua metode ini dilaksanakan secara simbiosis, dimana air limbah yang diciptakan produksi ikan dapat dipakai sebagai sumber air tanaman hidroponik, dan setelah dipakai tanaman hidroponik, mereka menghasilkan air yang telah disaring dan dapat dipakai lagi untuk aquaculture. Kelebihan dari sistem ini adalah penggunaan air yang jauh lebih hemat, dan sistem yang saling bekergantungan ini dapat bekerja secara otomatis mengikuti alur sistem yang ada, sehingga mengurangi keperluan sumber daya eksternal (Jena, Biswas, \& Saha, 2017).

\section{Arsitektur Berkelanjutan}

Arsitektur berkelanjutan adalah arsitektur yang meminimalisir efek negatif bangunan terhadap lingkungan dan bumi dengan efisiensi dan moderasi penggunaan material, serta desain yang mencerminkan \& mengimplementasi efisiensi energi (Gutierrez \& Hidalgo, 2020). Tujuan dari sustainable architecture sama seperti tujuan Sustainable Development Goals (SDG), yaitu untuk menciptakan bumi menjadi tempat yang lebih baik, serta untuk tidak meninggalkan seseorang dibelakang. Maksudnya adalah mengejar pengembangan keberlanjutan untuk semua. Mulai dari kesenjangan sosial, disabilitas, energi, pangan, ekonomi, sampai hukum. Terdapat 17 poin dalam SDG yang dapat diterapkan dalam arsitektur berkelanjutan, seperti di gambar berikut.

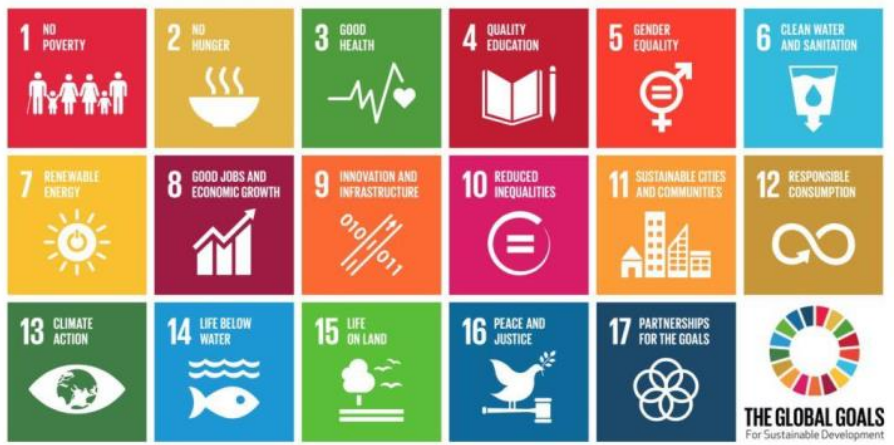

Gambar 3. 17 Poin SDG

Sumber: unicef.org 
Sebagai arsitek, harus merancang bangunan dengan sangat hati-hati karena bangunan juga sebab adanya polusi. Dengan menggunakan desain dan teknologi yang menjaga alam, maka polusi yang diciptakan bangunan akan menurun dikemudian hari. Aspek yang harus diperhatikan dari listrik dan air. Menggunakan perangkat listrik dapat mengurangi polusi dan energi. Pada bangunan sinar matahari harus cukup sehingga pada pagi dan siang hari tidak perlu menggunakan lampu. Dengan menggunakan lampu LED, konsumsi energi listrik akan rendah. Memperhatikan jumlah Air Conditioner (AC) tentu akan mengurangi polusi udara dan energi. Penggunaan energi yang efisien memiliki dampak yang besar dalam menjaga alam. Air juga merupakan kebutuhan dasar untuk hidup yang perlu digunakan dengan bijak. Tidak boros dalam menggunakan air dapat dimanfaatkan dengan mengolah dan menggunakan air kembali. Dengan teknologi pengolahan air, air dapat digunakan kembali meskipun tidak $100 \%$ bersih saaat digunakan pertama kali. Pemanfaatan air ini dapat digunakan untuk menyiram tanaman, dan sebagainya (Sassi, 2006).

\section{METODE}

\section{Metode Perancangan}

Berdasarkan pengembangan isu yaitu perlunya produksi pangan berkelanjutan di pemukiman padat, serta aspek berkelanjutan dikaitkan terhadap konsep utama bangunan, maka program yang diusulkan berupa fasilitas aquaponic publik dengan konsep komunitas. Menurut Edith Cherry FAIA, ASLA dan John Petronis AIA, AICP dalam pemograman suatu bangunan terdapat 6 tahapan proses yaitu riset tipe proyek, menentukan tujuan dan objektif, mengumpulkan informasi yang diperlukan, identifikasi strategi, menentukan kebutuhan kuantitatif, serta merumuskan program.

Dari keenam tahap tersebut 3 tahap pertama merupakan pengumpulan data berkaitan dengan urban farming khususnya aquaponic, terutama kebutuhan bangunan serta kemasan arsitektur yang cocok. Pengumpulanan data bersumber dari studi preseden proyek sejenis yang sudah terbangun di tempat lain, lalu juga pengkutipan standar-standar untuk fungsi aquaponic farming yang sudah ada. Program pun dapat terbentuk serta terwujudnya kriteria pangsa pasar proyek. Setelah menemukan pangsa pasar, maka dilakukan pencarian kawasan yang mempunyai demografis serta kriteria yang cocok untuk menjadi tapak proyek eksperimental. Studi tapak kemudian dilakukan untuk mengumpulkan data-data tapak yang akan diproses menjadi sebuah bentuk desain yang menjawab isu dan memenuhi program.

\section{Pemilihan Tapak}

Dalam pemilihan Kawasan untuk proyek ini, harus bertepatan dengan calon sasaran program yang tepat. Dengan isu keberlanjutan pangan bagi masyarakat perkotaan, maka kawasan harus mempunyai konsentrasi target market yang tepat. Kriteria tersebut antara lain harus dalam area pemukiman urban padat, dimana terdapat banyak konsentrasi rumah warga perkotaan, karena proyek dicanangkan berada di tengah-tengah komunitas warga perkotaan. Berdekatan dengan sungai/sumber air, untuk sumber daya utama bagi aktivitas penanaman. menghindari memompa air tanah agar tidak berdampak buruk bagi lingkungan, lalu juga mempunyai tanah yang relatif subur, agar tanah setempat dapat dijadikan medium tanam dan berbagai pangan bisa tumbuh secara optimal. 


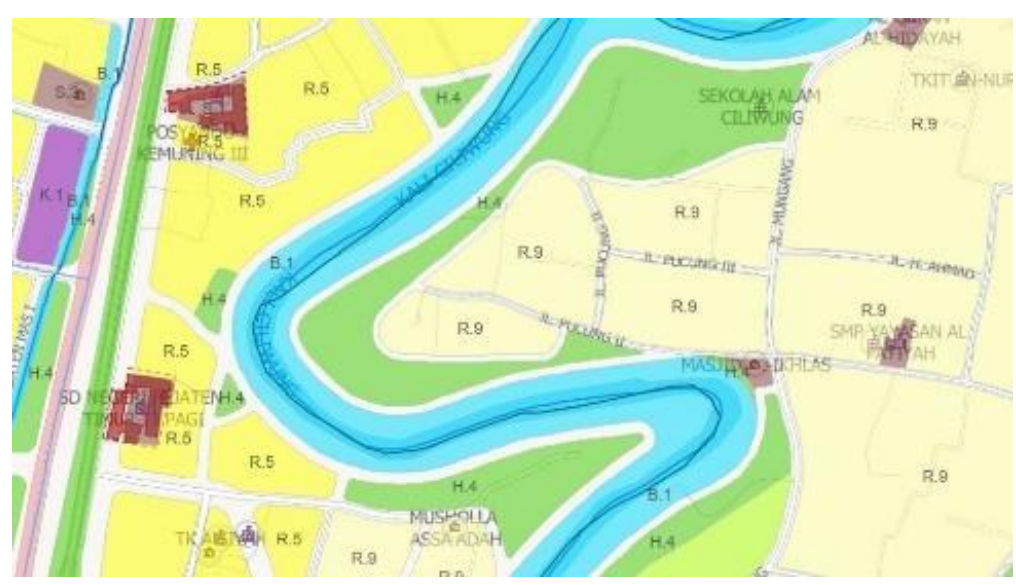

Gambar 4. Peta Rencana Kota Kawasan Balekambang Sumber: jakartasatu.jakarta.go.id

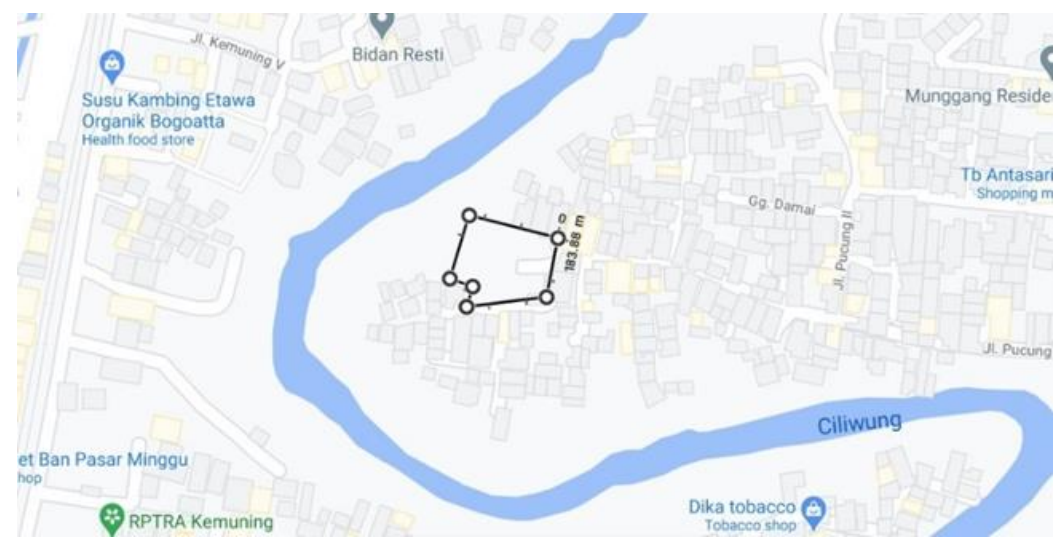

Gambar 5. Peta Kawasan dengan Tapak Sumber: maps.google.com

Area proyek eksperimental yang dipilih adalah Balekambang, Jakarta Timur. Balekambang dikenal sebagai area pemukiman yang relatif padat. Hampir semua area kelurahan diperuntukan untuk pemukiman, dengan pengecualian beberapa fasilitas umum. Balekambang mempunyai luasan 1,65 km², dengan populasi 32.083 jiwa, yang membuat kepadatan penduduk sekitar 19 Ribu Jiwa/Km. Kelurahan ini masih mempunyai area hijau yang cukup, terutama di pinggiran kali ciliwung, yang membatasi seluruh sisi timur kelurahan ini. Kawasan balekambang dan condet secara general masih mempunyai kondisi tanah yang masih subur.

Tapak berada di sisi timur kelurahan balekambang, tepatnya di RT 11 RW 2. Tapak berbatasan langsung dengan pinggiran hijau Sungai Ciliwung. Kontur tapak relatif rata, dan karena sungai ciliwung berada di bawah kontur tanah, maka ancaman banjir tidak terlalu ada. Tapak mempunyai luasan kurang lebih 1.800 meter, dengan batasan tapak yang minim di sisi timur. Pada Peta Rencana Kota, peruntukan tapak terpilih adalah zona perumahan KDB rendah (R9). Peruntukan dapat memenuhi fungsi hunian, fasilitas umum, komersil dan lahan hijau.

\section{DISKUSI DAN HASIL}

\section{Konsep}

Bangunan memiliki konsep utama penggabungan ruangan serta fasilitas tanam dengan ruang sosial bagi warga sekitar dengan bentuk shared space. Dengan konsep ini, diharapkan fasilitas tanam menjadi bagian dari keseharian warga sekitar, sehingga dapat menimbulkan rasa kepemilikan bersama warga atas fasilitasnya. Selain konsep shared space, bangunan mempunyai konsep desain yaitu maksimalisasi sumber daya alami untuk kegunaan fungsi. Pengudaraan 
serta pencahayaan alami didorong masuk kedalam bangunan untuk dipakai bagi medium tanam, serta untuk kenyamanan pengguna.

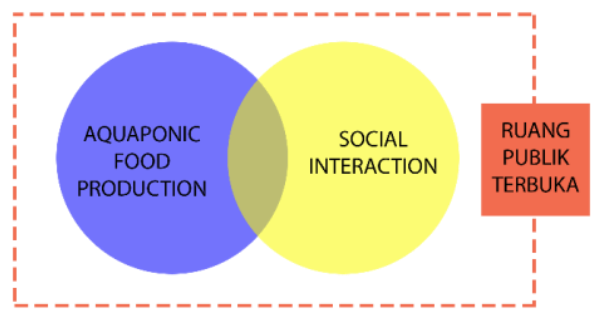

Gambar 6. Ilustrasi Konsep Proyek

Sumber: maps.google.com

\section{Proses Massing}

Pembentukan massa dimulai dengan sebuah massa utama berbentuk persegi panjang, yang memanjang mengikuti bentuk tapak yang panjang ke belakang. Kemudian massa dipecah menjadi 3 bagian sesuai fungsi, yaitu servis di bagian selatan, cocok tanam di bagian tengah, lalu area publik di bagian utara. Area publik diletakkan di sisi utara karena merupakan tempat interaksi publik warga, yang berdekatan dengan rumah mereka. Setelah pemecahan massa, maka dilakukan implementasi grid yang terdiri dari grid 6x6 meter. Implementasi grid dibuat untuk memperjelas keruangan serta adaptasi konstruksi struktur beton.

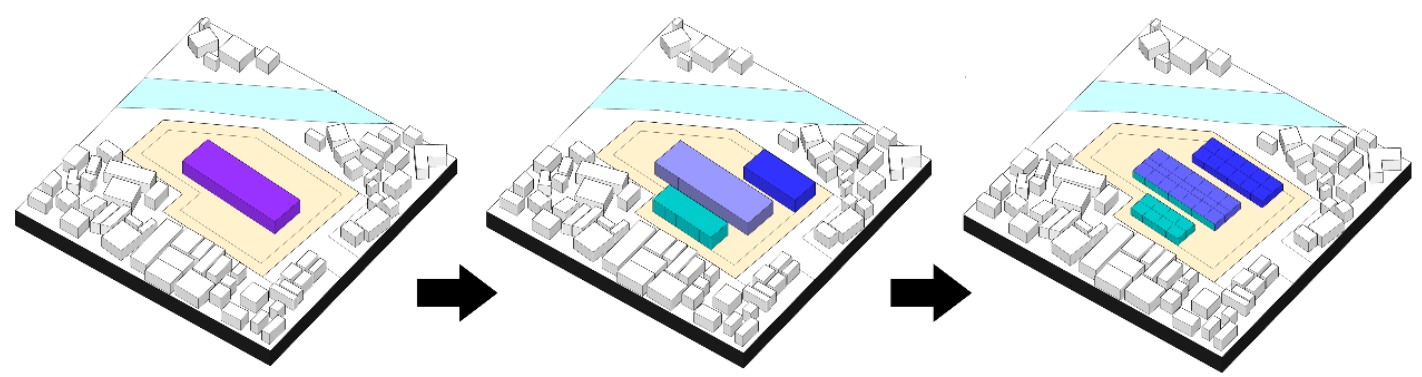

Gambar 7. Proses Pembentukan Massa 1

Sumber: Dokumen Pribadi, 2021

Kemudian massa ditinggikan sebanyak 2 dan 3 lantai agar lebih tinggi dari bangunan sekitar yaitu perumahan 1-2 lantai. Gunanya adalah untuk melancarkan cahaya matahari masuk tanpa terhalang bangunan sekitar. Lalu, proses massing dilanjutkan dengan pembentukan bentuk atap. Bentuk atap dibuat mengikuti perumahan sekitar yaitu atap pelana. Bentuk pelana memiliki 2 fungsi, yang pertama adalah kesan lokalitas dengan bangunan perumahan sekitar, dan yang kedua adalah antisipasi iklim lokasi dengan curah hujan yang tinggi. Terakhir, massa diberikan sentuhan akhir yaitu implementasi bukaan cahaya di atap untuk maksimalisasi cahaya masuk, serta penambahan konektor antar massa yang berada di tengah tapak.

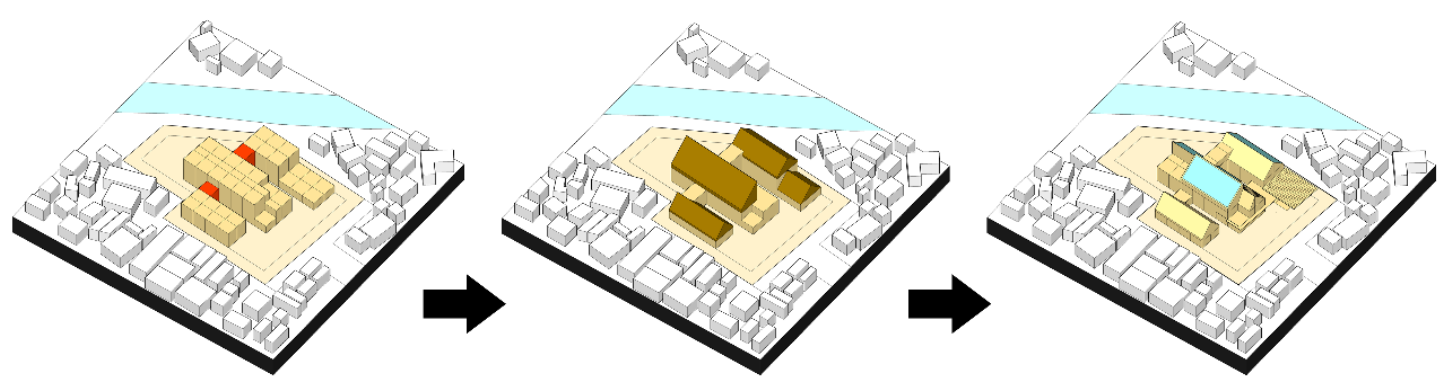

Gambar 8. Proses Pembentukan Massa 2

Sumber: Dokumen Pribadi, 2021 


\section{Hasil Rancangan}

Pada tapak, akses masuk ke dalam bangunan berada di sisi timur tapak, berbatasan dengan satusatunya akses masuk, yaitu Jl. Pucung 2. Sirkulasi kendaraan hanya dibatasi di sisi timur, terbatas terhadap drop off point di tengah, loading dock di selatan, dan parkir terbatas di sekitarnya. Jumlah parkir dibuat terbatas karena fungsi utama bangunan yang diperuntukan untuk warga sekitar, yang dapat mengakses bangunan dengan berjalan kaki dari rumah. Karena ini pula ada akses sekunder terhadap bangunan dari area publik di utara, yang langsung berbatasan dengan rumah warga.

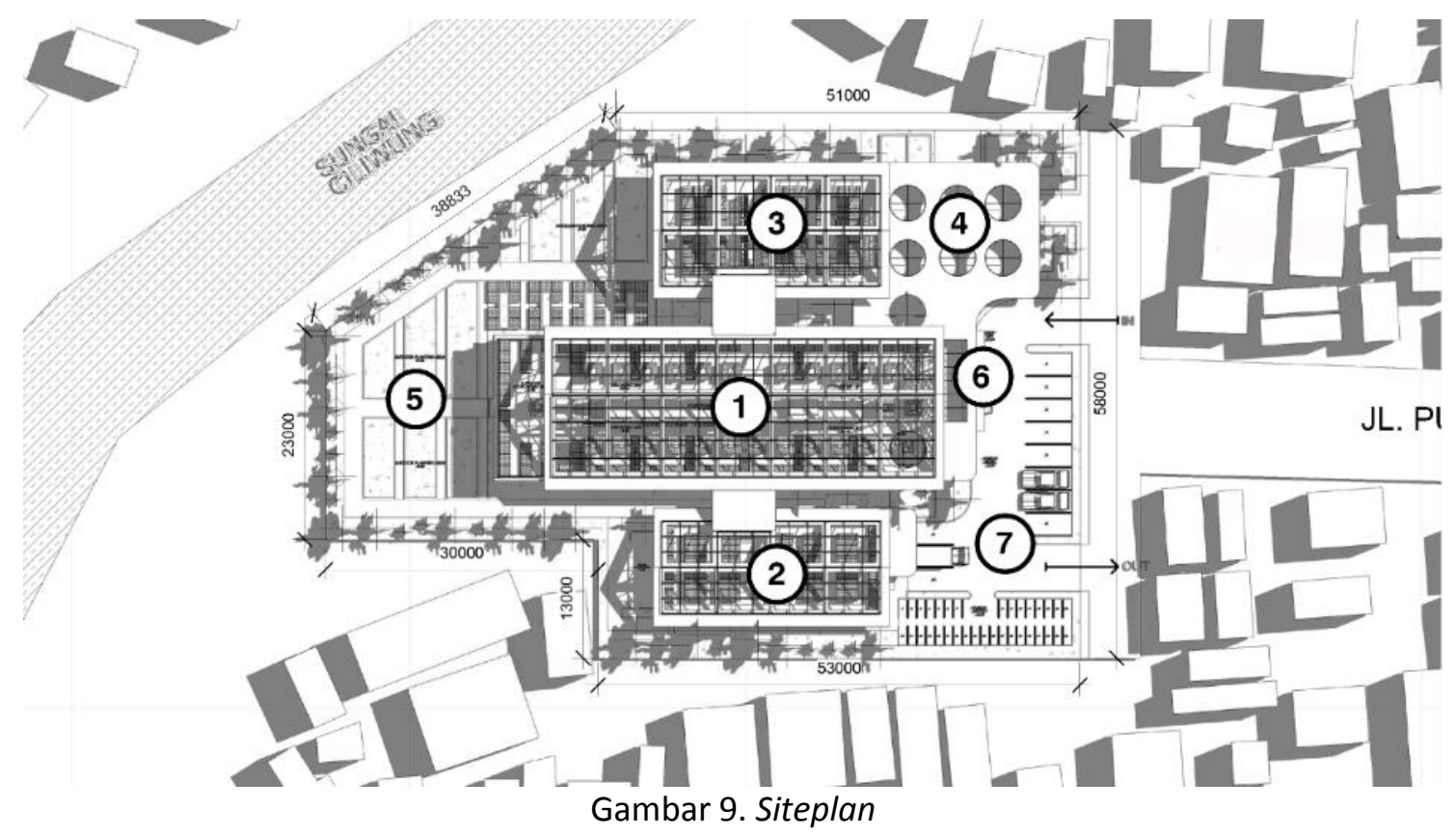

Sumber: Dokumen Pribadi, 2021

Keterangan :
1. Bangunan tanam utama
2. Bangunan servis
3. Bangunan publik
4. Ruang publik terbuka

5. Ruang tanam outdoor

6. Area penurunan pengunjung

7. Loading dock \& parkir

Ruangan tanam utama dibagi menjadi 3 area berdasarkan lantai. Di lantai dasar, penempatan tangki ikan untuk proses aquaculture. Sementara di lantai 2 dan 3 ditempatkan modul-modul hidroponik untuk tanaman. Pembagian penempatan modul hidroponik dibagi sesuai intensitas cahaya yang dibutuhkan. Tanaman dengan keperluan cahaya terendah (4 jam matahari) ditempatkan di lantai 2 yang bukaan cahaya nya lebih sedikit, sementara di lantai 3 ditempatkan tanaman yang memerlukan cahaya lebih ( 6 dan 8 jam matahari). 


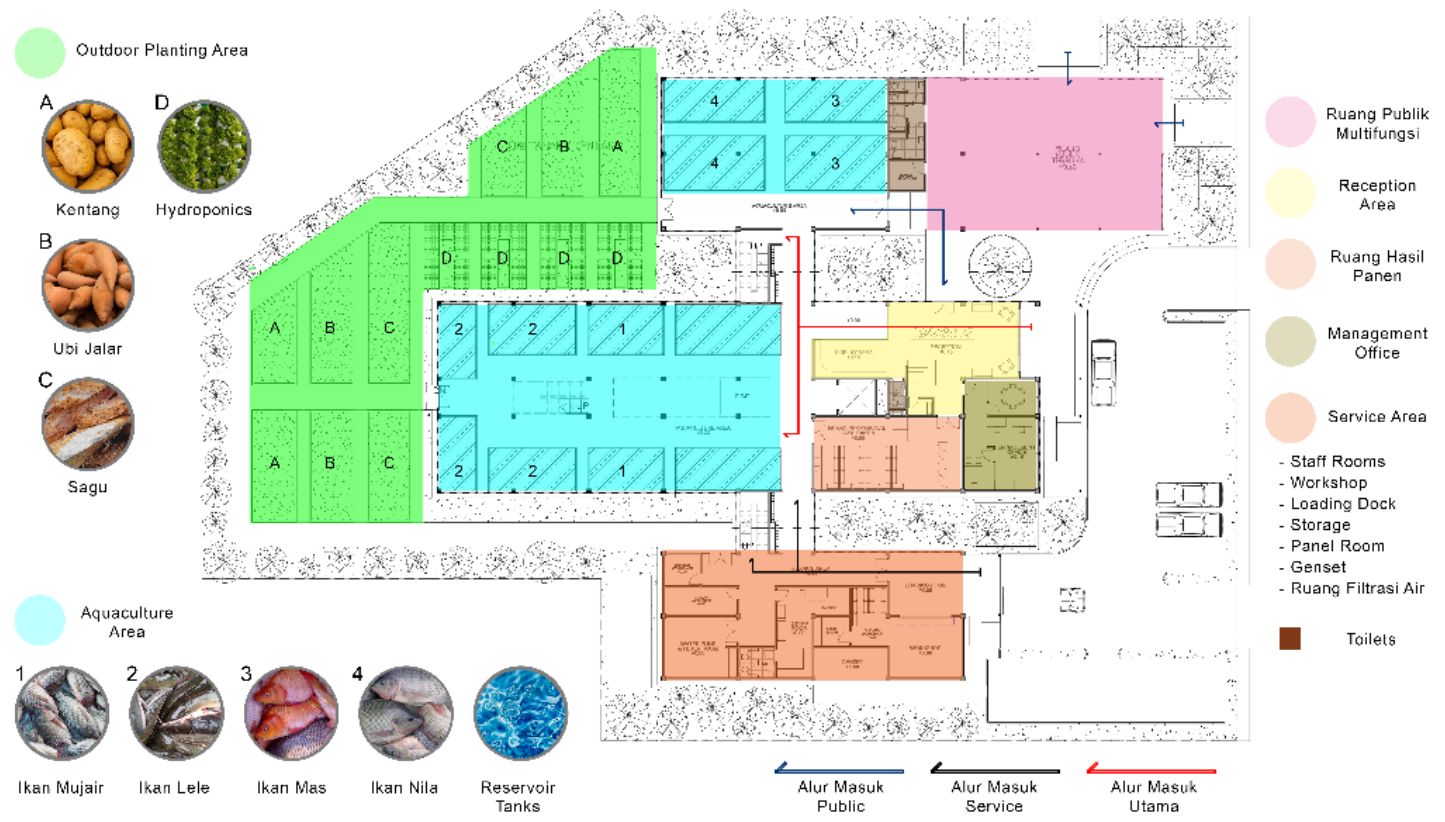

Gambar 10. Denah Sequence Lantai 1

Sumber: Dokumen Pribadi, 2021

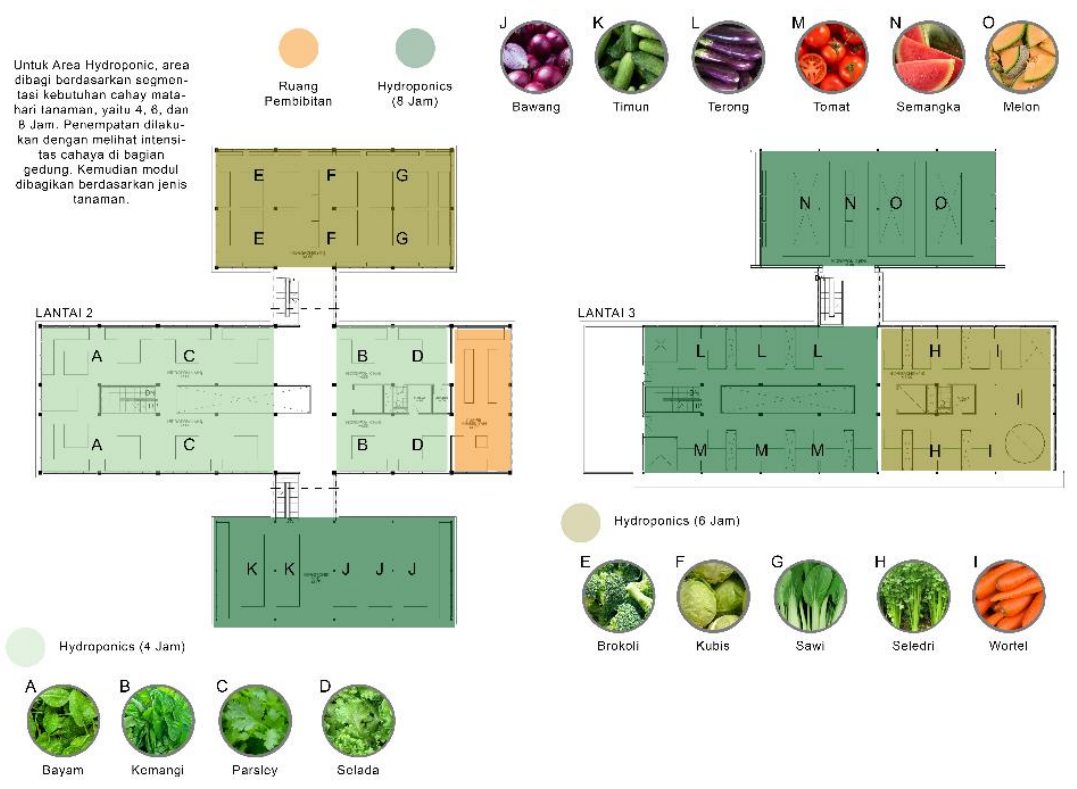

Gambar 11. Denah Sequence Lantai 2 \& 3

Sumber: Dokumen Pribadi, 2021

Sistem aquaponic sendiri memerlukan sirkulasi air antara tangki ikan (aquaculture) dengan tanaman (hidroponik) secara konstan. Sistem pemipaan mengalir antara kedua entitas ini, dengan sirkulasi pipa vertikal terpusat di void tengah bangunan tanaman utama. Sistem pemipaan, terutama yang vertikal dibangun terbuka agar warga dapat melihat serta mengerti bagaimana sistem ini bekerja. Selain sistem pemipaan, sumber air sekunder juga dipikirkan. Air dari Sungai Ciliwung, koleksi air hujan, di tangki cadangan untuk kemudian diproses menjadi air bersih. 


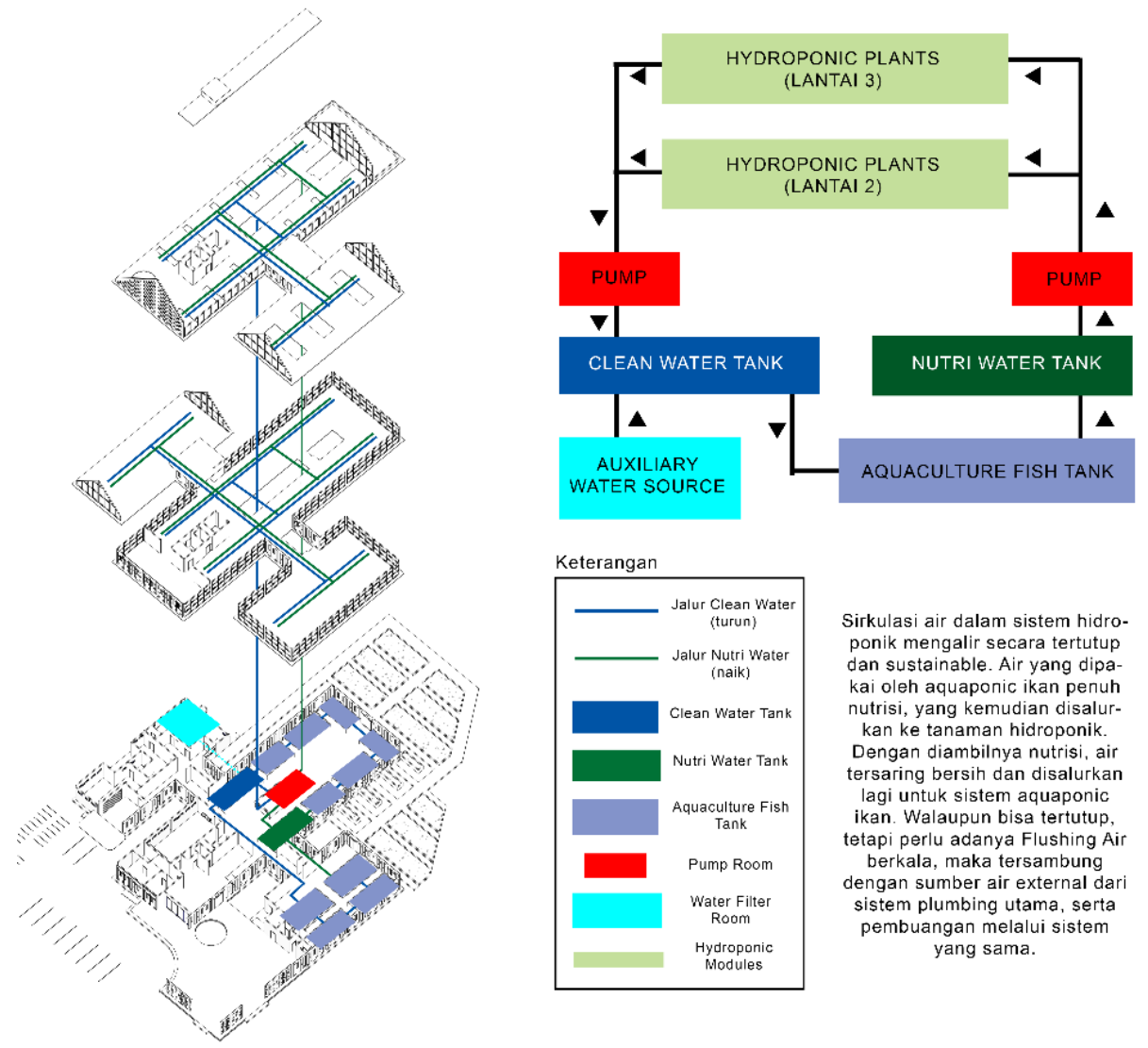

Gambar 12. Bagan Utilitas Aquaponic

Sumber: Dokumen Pribadi, 2021

Selain sistem pemipaan, kebutuhan untuk tanaman aquaponic juga dipenuhi dari aspek desain gedung itu sendiri. Untuk cahaya matahari, atap yang transparan menyalurkan matahari secara langsung terhadap tanaman yang ada di lantai 3, dan lantai void menyalurkannya ke lantai 2. Selain dari sisi atas, façade yang didominasi oleh kaca curtain wall juga menyalurkan cahaya lebih baik. Untuk pengudaraan, façade curtain wall kaca dibuat dengan lubang di beberapa panel agar udara dapat masuk kedalam bangunan secara lancar. Juga penerapan second skin perforated steel sheet menyalurkan pengudaraan dengan tetap memberi batasan ruang.

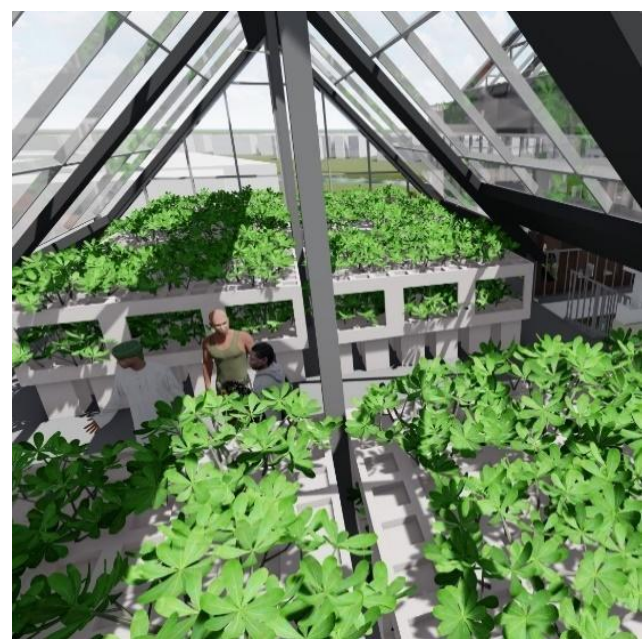

Gambar 13. Area Hidroponik Sumber: Dokumen Pribadi, 2021

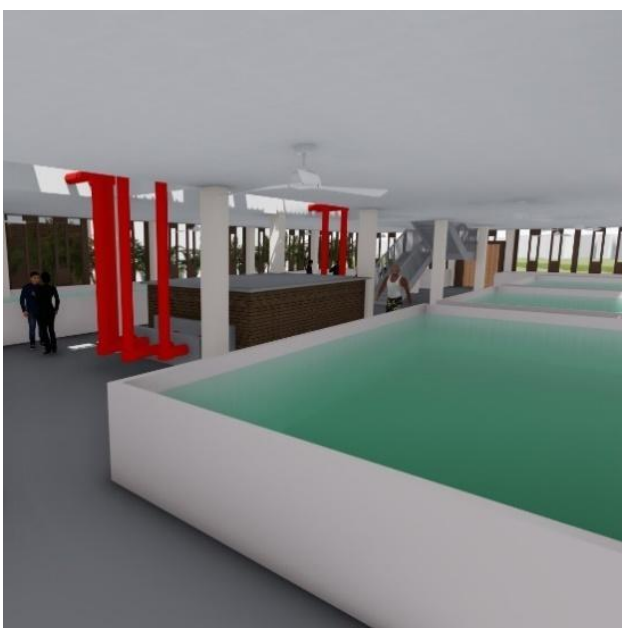

Gambar 14. Area Aquaculture Sumber: Dokumen Pribadi, 2021 
Tanaman yang sudah diproduksi dari fasilitas ini kemudian disimpan di dalam ruang penyimpanan pangan. Kemudian pangan dibagikan ke warga atau diperjual-belikan kepada pengunjung, kedua aktivitas ini berlangsung di ruang publik terbuka.

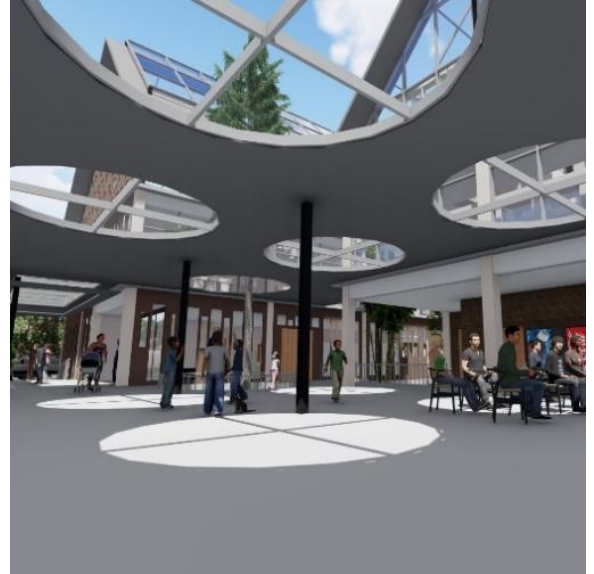

Gambar 15. Area Publik Terbuka Sumber: Dokumen Pribadi, 2021

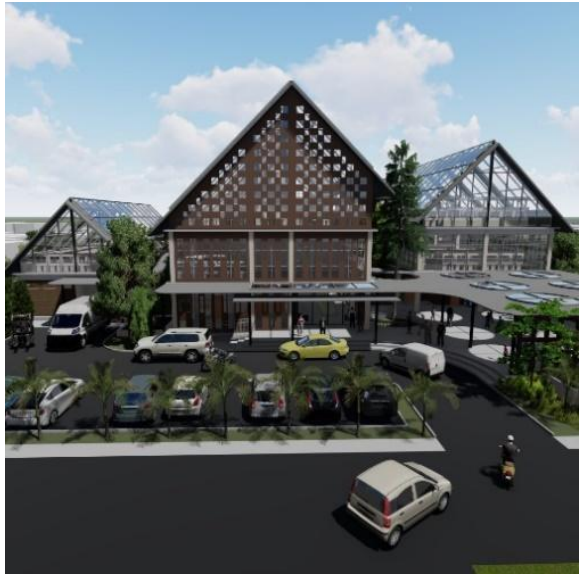

Gambar 16. Façade Depan

Sumber: Dokumen Pribadi, 2021

Bangunan dilengkapi pula dengan berbagai fasilitas pendukung. Area resepsi di depan bangunan tanaman utama berfungsi menjadi entrance formal ke gedung fasilitas. Area servis dilengkapi dengan pergudangan, workshop, ruang genset, ruang pompa hingga ruang istirahat karyawan. Akses vertikal bagi pengguna menggunakan tangga di 3 titik tengah serta sebuah lift.

\section{KESIMPULAN}

\section{Kesimpulan}

Pangan sangatlah berpengaruh terhadap kehidupan manusia, serta ekologi bumi itu sendiri. Pangan mendukung manusia untuk melakukan aktivitas sehari-hari dan menjamin kelangsungan kehidupan manusia serta lingkungannya. Produksi pangan pun mempengaruhi banyak sekali faktor, seperti sumber daya alam, lahan, hingga ekosistem bumi. Maka dalam memproduksi pangan, kita harus melihat apa dampak pangan secara holistik terhadap berbagai faktor alam. Produksi pangan secara berkelanjutan bertujuan untuk menyeimbangkan manfaat bagi konsumen manusia, serta efek positif bagi sumber daya alam. Maka dari itu, implementasi pangan berkelanjuta dalam kehidupan sehari-hari harus digalakkan dalam masyarakat, terutama masyarakat perkotaan padat. Dengan volume konsumsi pangan yang tinggi, perubahan sikap konsumsi makanan masyarakat urban dari konvensional menjadi berkelanjutan, akan sangat berpengaruh terhadap rotasi produksi pangan serta penggunaan sumber daya alam itu sendiri. Salah satu caranya adalah dengan memproduksi pangan sendiri di perkotaan, dengan metode produksi yang ramah lingkungan dan efisien, yang menjadi tujuan utama fasilitas elsperimental ini. Fasilitas eksperimental ini bertujuan untuk membuat produksi pangan berkelanjutan menjadi sesuatu yang dibiasakan dan dimiliki oleh warga sekitarnya yang merupakan target audiens. Produksi pangan in-situ digabungkan dengan aktivitas sosial warga sehari hari, dan pelan-pelan terintegrasi dengan kehidupan warga sekitar. Harapannya dengan terwujudnya fasilitas ini, warga mempunyai rasa kepemilikan atas fasilitas serta proses penanaman dapat menjadi bagian dari aktivitas keseharian warga, dan hasil olahannya dapat dimanfaatkan maksimal oleh warga lokal sekitar, serta mempercepat implementasi pangan berkelanjutan dalam kehidupan masyarakat secara luas. 


\section{Saran}

Proyek ini dapat membantu masyarakat urban jakarta untuk mengenal serta mengimplementasikan pangan berkelanjutan didalam kehidupan mereka sehari-hari. Dengan populasi masif yang mendorong konsumsi pangan yang besar, maka efek perubahan konsumsi pangan masyarakat urban jakarta dapat terasa tidak hanya di level mikro, tetapi di level makro pula. Saran saya adalah proyek ini dibuat di berbagai kelurahan di jakarta, terutama kelurahan dengan kepadatan penduduk tinggi. Tidak terbatas pula bisa beberapa fasilitas dibangun dalam satu kelurahan, semua dapat disesuaikan dengan populasi keluarahan tersebut. Lalu juga disarankan setiap rukun warga maupun rukun tetangga yang diimplementasikan program ini diberikan pelatihan yang mumpuni untuk mengoperasikan serta menyalurkan ilmunya ke warga sekitar, agar produksi pangan berkelanjutan secara mandiri dapat menjadi bagian dari kehidupan warga urban jakarta.

\section{REFERENSI}

Burgess, A., \& Glasauer, P. (2004). Family Nutrition Guide. Rome: Food \& Agriculture Organization.

Capra, F. (1996). The Web of Life : A New Scientific Understanding of Living Systems. New York: Anchor Books.

Cockrall-King, J. (2012). Food and The City : Urban Agriculture and the New Food Revolution. New York: Promotheus Books.

Coman, M., \& Cioruta, B. (2019). From Human-Enviroment Interaction to Enviromental Informatics : the Social-Ecological Systems Dynamics in Knowledge-Based Society. Hidraulica, 12.

Devall, B. (1985). Deep Ecology : Living as if Nature Mattered. Salt Lake City: Gibbs M Smith Inc. Food \& Agriculture Organization. (2011). The Place for Urban and Peri-Urban Agricultures in National Food Security Programmes. Rome: Food \& Agriculture Organization.

Gutierrez, R. U., \& Hidalgo, L. d. (2020). Elements Of Sustainable Architecture. New York: Routeledge.

Holt-Gimenez, E. (2019). Capitalism, Food, and Social Movements : The Political Economy of Food System Transformation. Journal of Agriculture, Food Systems, and Community Development, 13.

Jena, A. K., Biswas, P., \& Saha, H. (2017). Advanced Farming Systems In Agriculture : Strategies To Enhance The Production. Innovative Farming, 7.

Kalantari, F., Tahir, O. M., Lahijani, A. M., \& Kalantari, S. (2017). A Review of Vertical Farming Technology : A Guide for Implementation of Building Integrated Agriculture in Cities. Advanced Engineering Forum, 16.

Neven, D. (2014). Developing Sustainable Food Chains - Guiding Principles. Rome: Food \& Agriculture Organization.

Riawan, N. (2016). Step by Step Komplet Membuat Instalasi Akuaponik Portabel 1 m2 Hingga Memanen. Jakarta: AgroMedia Pustaka.

Sassi, P. (2006). Strategies for Sustainable Architecture. New York: Taylor \& Francis. 
